Abbreviated Key Title: Sch J Med Case Rep

ISSN 2347-9507 (Print) | ISSN 2347-6559 (Online)

Journal homepage: https://saspublishers.com/sjmcr/

\title{
Rare Cause of Acute Peritonitis: Cystic Intestinal Pneumatosis
}

Abdelmounim Elkhamri*, Jakhlal Youssef, Lahlou Khaled, Settaf Abdellatif, Benamr Said, Mssrouri Rahal, Mdaghri Jalil

Surgical Department B, Faculty of Medicine and Pharmacy, Mohammed 5 University, Ibn Sina Hospital, Rabat, Morocco

DOI: $10.36347 /$ simcr.2020.v08i09.003

| Received: 08.08.2020 | Accepted: 17.08.2020 | Published: 04.09.2020

*Corresponding author: Abdelmounim Elkhamri

\section{Abstract}

Case Report

Intestinal cystic pneumatosis is a rare disease characterized by the presence of gas cysts in the intestinal wall which can reach the digestive tract, with predilection for the intestine, of usually benign evolution. The diagnosis is evoked on the scanner, being able to avoid a surgical operation in urgency except complications. One reports here a rare case of cystic colonic pneumatosis, source of acute abdomen which imposed a surgical operation.

Keywords: Acute Peritonitis, Cystic, Pneumatosis.

Copyright @ 2020: This is an open-access article distributed under the terms of the Creative Commons Attribution license which permits unrestricted use, distribution, and reproduction in any medium for non-commercial use (NonCommercial, or CC-BY-NC) provided the original author and source are credited.

\section{INTRODUCTION}

Intestinal cystic pneumatosis is rare as a pathology defined by the presence of cysts of gas content in the intestinal wall [1], which remains poorly understood, posing diagnostic and therapeutic problems $[1,2]$. Here we present an observation of a primitive PKI revealed by acute peritonitis.

\section{Patient and Observation}

The patient is a 40-year-old with acute abdominal pain. The patient has no specific medical or surgical history. Clinical examination found an acute abdomen, contracted on palpation. An abdominal CT scan was ordered showing just abundant pneumoperitoneum (figure 1). On surgical examination, cystic pneumatosis was noted throughout the whole gilt (figure 2), and there were no perforations of a digestive hollow organ. The surgical procedure was limited to lavage + drainage. The postoperative sequelae were simple.

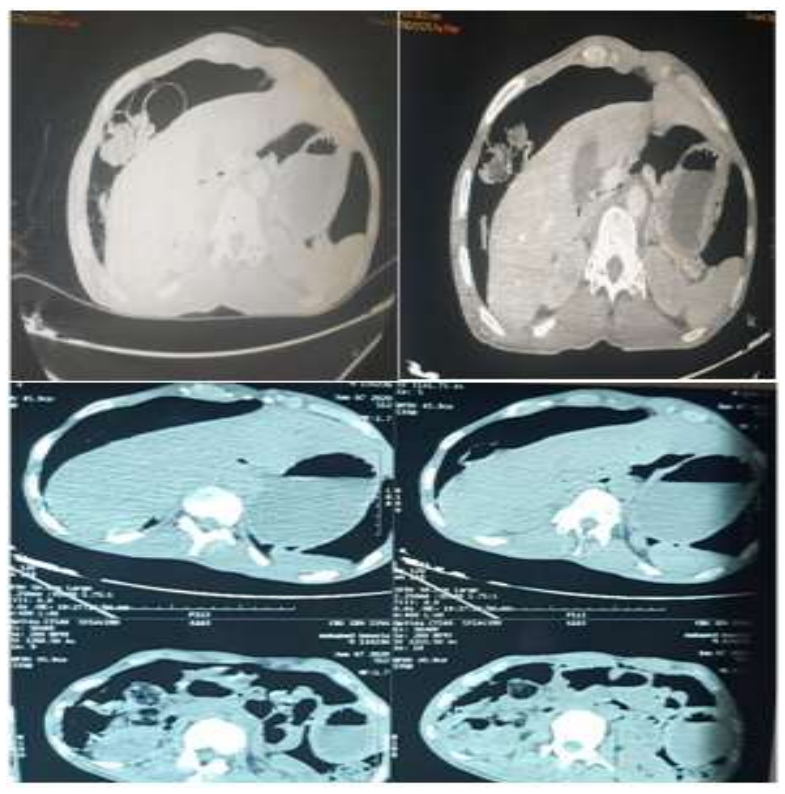

Fig-1
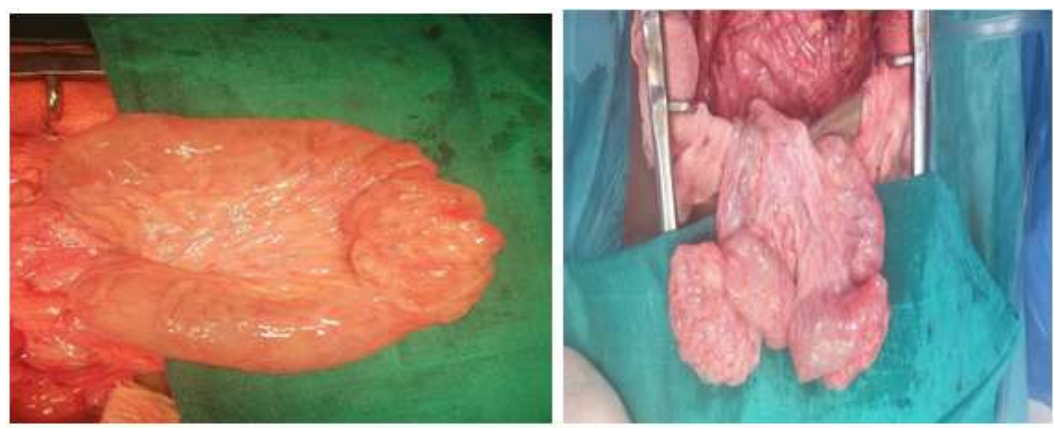

Fig-2 


\section{DISCUSSION}

Intestinal cystic pneumatosis is a very rare pathology characterized by the presence of gas cysts in the intestinal wall which can reach the entire digestive tract, with a predilection for the small intestine and the colon [1]. The attacks are mainly developed in the submucosa, in particular in colic attacks, and/or in the subserous membrane, in particular in the area of the hare. They can have other localizations: mesentery in the sub-peritoneal cellulo-fatty spaces of the retroperitoneum and the abdominal walls, which can lead to pneumoperitoneum [2]. This is the case of our patient where abundant interhepatodiaphragmatic pneumoperitoneum has been noted.

PKI mostly affects men between 40 and 50 years of age and can be associated or secondary to other gastrointestinal (abdominal trauma, inflammatory bowel diseases) or extra-gastrointestinal (lupus, periarteritis nodosa) pathologies, as well as primary [3].

For our patient we are faced with a primitive cystic pneumatosis since the patient has no previous history of it. The mechanism of constitution and maintenance of gas cysts is multifactorial.

PKI is generally symptomatic pauci. It can be revealed by non-specific signs in $30 \%$ of cases: diarrhoea, bloody or mucous stools, meteorism, vomiting, constipation, and tenesmus. Peritonitis by perforation is a rare complication related to the volume of cysts [5]. CT scans generally allow a precise diagnosis to be made. It can show images of gas density in the digestive wall. Multi-planar reconstructions allow the precise study of the topography, volume and extent of cysts [6].The presence of pneumoperitoneum is pathognomonic. In the case of our patient the CT scan only showed that there is pneumoperitoneum and did not make the diagnosis of intestinal cystic pneumatosis. Endoscopic examinations can visualize submucosal cysts that produce a characteristic noise when collapsed by the biopsy forceps. On abdominal CT scan, we can differentiate acute intestinal pneumatosis from acute cystic pneumatosis by the disappearance of airway [6].

The treatment is most often a medical treatment whose aim is to reduce or eliminate cysts by reducing the anaerobic bacteria that cause them. It uses hygieno-dietary measures, antibacterial antibiotic therapy with metronidazole [7, 3] and hyperbaric oxygen therapy. Surgical treatment is indicated in case of complications, cases that are refractory to medical treatment and in case of associated surgical pathology; it consists in resecting the intestinal segment by laparotomy or by laparoscopy.

Our patient was operated for suspicion of peritonitis by perforation of a hollow organ. He benefited from an abundant wash + wide drainage. The postoperative follow-up was simple without complications.

\section{CONCLUSION}

$\mathrm{PKI}$ is a rare condition, in the majority of cases asymptomatic. It must be recognized to avoid abusive therapeutic interventions. It remains a rare cause of acute abdomen, whose diagnosis is based on $\mathrm{tdm}$.

\section{REFERENCES}

1. Goel A, Tiwari B, Kujur S, Ganguly PK. Pneumatosis cystoides intestinalis .World J Gastroenterol. 2011;17(44):4932-4936.

2. Behnoush B, Bazmi B, Mohammadi F, Bazmi E, Dorvashi GA.Pneumatosis Intestinalis: Autopsy Finding. Acta Medica Iranica.2009;47(5):415-417.

3. Serraj I, El kihal N, Mohcine R, Essaid A. Pneumatose kystique intestinale avec ascite : association exceptionnelle. ActaEndoscopica. 2006;36(3):357-362.

4. Rivera Vaquerizo PA, Caramuto Martins A, Lorente García1 MA,Blasco Colmenarejo $M$ and Pérez Flores R. Pneumatosiscystoides intestinalis. Rev Esp Enferm Dig. 2006;98(12):959-961.

5. Lê P, Benazzouz A, Fritsch L. Une pneumatose kystique colique révélée par un syndrome pseudo occlusif. Ann Chir.2003;128(2):117-120.

6. Braham R, Said M, Rehaiem A, Jerbi Omezzine S, Memmi F, Bouabid Z. Imagery of pneumatosis cystica intestinalis. JChir. 2004;14(3):201- 204.

7. El Bouhaddouti H, Ousadden A, Benjelloun B, Mazaz K,et Aït Taleb K. Pneumatose kystique iléale révélée par un volvulus du grêle. Pan Afr Med J. 2010;6:9. 